\section{РАЗГРАНИЧЕНИЕ ДЕЙСТВИЯ ИНСТИТУТОВ ОБЩЕСТВЕННОГО ДОСТОЯНИЯ И СИРОТСКИХ ПРОИЗВЕДЕНИЙ В ТРАНСГРАНИЧНЫХ АВТОРСКИХ ОТНОШЕНИЯХ}

\begin{abstract}
Аннотация. Институты общественного достояния и сиротских произведений в трансграничных авторских отношениях привлекают особое внимание доктрины в связи с тем, что это механизмы, способные преодолевать территориальность. В статье поставлена задача разграничить действие этих институтов на основании исследования истории вопроса, содержания источников, режимов правового регулирования. Сделаны выводы о различиях по следующим критериям: 1) признанность мировым сообществом - институт общественного достояния универсален, тогда как институт сиротских произведений закреплен на национальном (региональном) уровне лишь в нескольких государствах;

2) случаи перехода произведений под действие институтов в общественное достояние: истечение срока охраны, законодательные предписания санкционного характера, добровольный отказ авторов от исключительных прав; институт сиротских произведений - нежелание автора осуществлять контроль или утрата сведений об авторе; 3) на основании определений объектов регулирования: общественное достояние - произведения, которые не находятся под охраной авторского права; сиротские произведения, напротив, предположительно находятся под охраной авторского права;

4) связь с процессом гармонизации - институт общественного достояния закреплен в праве всех государств мира, участвующих в системе международной охраны авторских прав, и его действие можно считать результатом гармонизации, включая выбор lех lосі protectionis для разрешения трансграничных споров; в механизме доступа к сиротским произведениям единообразие отсутствует. При этом на трансграничном уровне оба института объединяет проблема отсутствия правового регулирования для ситуации возврата произведения под полноценную авторско-правовую охрану.
\end{abstract}

Ключевые слова: сиротские произведения, коллизионное регулирование, трансграничные авторские отношения, общественное достояние, авторское право, международное частное право.

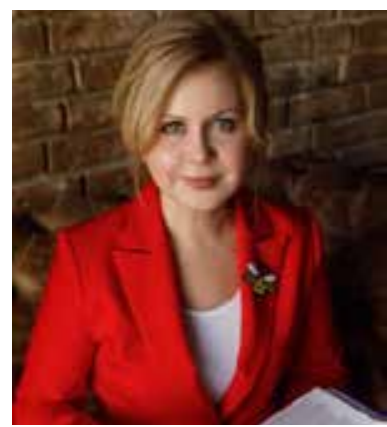

\section{Оксана Викторовна ЛУтКОВА,}

профрессор кафедры международного частного права

Университета имени О.Е. Кутафрина (МГЮА), доктор юридических наук, доцент ovlutkova@msal.ru 125993, Россия, г. Москва, ул. Садовая-Кудринская, д. 9

\title{
DOI: 10.17803/2311-5998.2021.79.3.049-060
}




\title{
O. V. LUTKOVA,
}

Professor of the Chair of Private International Law of the Kutafin Moscow State Law University (MSAL),

Dr. Sci. (Law), Associate Professor

ovlutkova@msal.ru

125993, Russia, Moscow, ul. Sadovaya-Kudrinskaya, 9

\section{DIFFERENTIATION OF INSTITUTIONS OF PUBLIC DOMAIN AND ORPHAN WORKS IN A CROSS-BORDER COPYRIGHT RELATIONS}

\begin{abstract}
Institutions of the public domain and orphan works in cross-border copyright relationships have drawn particular doctrinal attention because they are mechanisms capable of transcending territoriality. The article sets the task of distinguishing between the action of these institutions based on the study of the history of the issue, the content of sources, legal regulation regimes. Conclusions are made about the differences according to the following criteria:

1) recognition by the world community - the institution of the public domain is universal, while the institution of orphan works is enshrined at the national (regional) level only in a few states;

2) cases of transition of works under the influence of institutions - into the public domain - expiration of the term of protection, legislative prescriptions of a sanctioning nature, voluntary refusal of the authors from exclusive rights; institution of orphan works - the unwillingness of the author to exercise control or loss of information about the author;

3) on the basis of the definitions of the subjects of regulation: public domain - works that are not protected by copyright; orphan works, by contrast, are believed to be protected by copyright;

4) connection with the harmonization process - the institution of the public domain is enshrined in the law of all states of the world participating in the system of international copyright protection, and its action can be considered the result of harmonization, including the choice of lex loci protectionis to resolve cross-border disputes; there is no uniformity in the mechanism for accessing orphan works. At the same time, at the transboundary level, both institutions are united by the problem of the absence of legal regulation for the situation of returning a work under full copyright protection.
\end{abstract}

Keywords: orphan works, conflict regulation, transborder copyright relations, public domain, copyright, private international law.

настоящее время в доктрине международного авторского права значительное внимание обращено на институты правового регулирования, так или иначе выходящие за пределы национальных систем авторского права отдельных государств - институт общественного достояния и институт сиротских произведений. Такой интерес объективно обусловлен изначально 


\begin{tabular}{|c|c|}
\hline 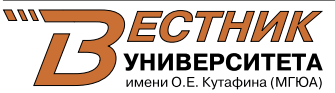 & $\begin{array}{l}\text { Луткова О. В. } \\
\text { Разграничение действия институтов обцественного достояния } \\
\text { и сиротских произведений в трансграничных авторских отношениях }\end{array}$ \\
\hline
\end{tabular}

«территориальным» ${ }^{1}$ характером охраны интеллектуальных, в том числе авторских, прав в трансграничных отношениях и, соответственно, поиском правовых механизмов, способных в какой-то мере преодолевать территориальность и унифрицировать/гармонизировать подходы государств к регулированию отношений по поводу результатов интеллектуальной деятельности.

Такими правовыми механизмами являются, в частности, институт общественного достояния и институт сиротских произведений. Поскольку в современной правовой доктрине действие этих институтов в ряде случаев описывается как переходное состояние из «сиротства» в общественное достояние ${ }^{2}$, автор настоящего исследования в целях избежания смешения ставит задачу разграничить действие институтов общественного достояния и сиротских произведений на основании анализа правовых режимов, соответствующих каждому из них.

Институт общественного достояния в трансграничном аспекте впервые был закреплен в ст. 18 (1) Бернской конвенции по охране литературных и художественных произведений 1886 г. $^{3}$ (далее - Бернская конвенция 1886 г.). В самом обобщенном смысле под общественным достоянием понимаются произведения, в отношении которых истек срок авторско-правовой охраны. В этом контексте институт общественного достояния вошел в национальное законодательство участвующих в международной системе охраны авторских прав государств ${ }^{4}$.

Институт сиротских произведений в настоящее время не отражен в международных соглашениях универсального характера, он закреплен только в некоторых региональных и национальных юридических документах. Впервые институт был зафиксирован в Директиве Европейского парламента и Совета Европейского Союза 2012/28/EC от 25 октября 2012 г. об определенном разрешенном использовании произведений, не определяемых по субъекту авторского права, в соответствии с которой «произведения... считаются не определяемыми по субъекту авторского права, если ни один из правообладателей такого произведения... не известен или не обнаружено местонахождение ни одного из известных правообладателей в результате добросовестного поиска, проведенного и зафиксированного»

1 О территориальности см., в частности: Луткова О. В. Принципы правового регулирования трансграничных авторских отношений // Вестник Университета имени О.Е. Кутафина (МГЮА). 2016. № 12 (28). С. 63-92.

2 См. об этом, в частности: Левова И. Ю., Винник Д. В., Моисеева А. Ю. Сиротские произведения в России: статус, пути решения проблемы : Как открыть доступ к произведениям, авторов или законных правообладателей которых установить невозможно. М., 2016 ; Пузин Р. С. Проблема перехода сиротских произведений в общественное достояние // Вестник Самарской гуманитарной академии. Серия «Право». 2018. № 1 (20). С. 158.

3 Институт общественного достояния не предусмотрен во Всемирной конвенции об авторском праве 1952 г., в Соглашении по торговым аспектам прав интеллектуальной собственности 1994 г. только единожды упоминается этот термин, в Договоре ВОИС по авторскому праву 1996 г. он отсутствует.

4 См. об этом также: Луткова О. В. Общественное достояние в международном авторском праве // Интеллектуальная собственность. Авторское право и смежные права. 2016. № 3. C. $45-58$. 
(ст. 2). В современном мире законодательные акты, включающие нормы института сиротских произведений, имеют менее 30 государств.

В соответствии со ст. 18 (1) Бернской конвенции 1886 г. основанием для перехода произведения в общественное достояние является истечение срока его охраны в стране происхождения, что в силу проблемы территориальности авторских прав не означает автоматическое приобретение аналогичного статуса и в других государствах. Каждое государство-участник самостоятельно определяет условия перехода произведений в общественное достояние и его регулирование посредством международных соглашений или национального права.

Этот вывод коррелирует с генеральным правилом Бернской конвенции (ст. 5(2)), в соответствии с которым пользование авторскими правами и их осуществление «не зависят от существования охраны в стране происхождения произведения» и «объем охраны, равно как и средства защиты, предоставляемые автору для охраны его прав, регулируются исключительно законодательством страны, в которой истребуется охрана».

Конвенционное правило, связывающее переход произведения в общественное достояние с территорией конкретного государства, предопределено национальнотерриториальным подходом к охране: произведения, включая произведения иностранных авторов, не охраняются автоматически, но лишь при соответствии определенным критериям. Иностранные произведения, которым не предоставляется охрана на территории принимающего государства, изначально включаются таким государством в сферу общественного достояния (Австралия, Бразилия, Дания, Кения, Китай, Корея, Коста-Рика, Малайзия, Соединенные Штаты Америки, Чили).

Так, на основании Закона об авторском праве Кении в общественное достояние напрямую включены «иностранные произведения, которые не пользуются охраной в Кении» (ст. 45(1))5. В некоторых государствах предусмотрены изъятия произведений иностранных авторов из-под охраны в в случае, если в государствах гражданства этих авторов отсутствует достаточный уровень охраны произведений для иностранных авторов (Италия, Руанда, Францияб $)$.

Произведение может перейти в общественное достояние не только в силу юридических предписаний, но и по воле правообладателя. В Чили и Кении право автора отказаться от охраны исключительных прав включено в законодательно сформулированное понятие общественного достояния ${ }^{7}$. В законодательстве Кореи предусмотрена возможность автора передать свои права в дар министру культуры и туризма как официальному представителю государства, который поручает управление этими правами в некоммерческих целях государственному органу — Комиссии по авторским правам ${ }^{8}$.

5 Закон об авторском праве Кении № 122001 г. // URL: http://www.wipo.int/wipolex/ru/details. jsp?id=2693 (текст на английском языке).

6 См.: Ancel M. E. France // Intellectual Property and Private International Law: Comparative Perspectives / ed. by T. Kono. Oxford and Portland, Oregon, 2012. P. 527.

7 Закон об авторском праве Кении № 122001 г.

8 Дюсолье С. Обзорное исследование по авторскому праву и смежным правам и общественному достоянию / Комитет по развитию и интеллектуальной собственности. 7-я сессия. Женева, 2-6 мая 2011 г. С. 35. См. также: Lee G. Korea // Intellectual Property and 
Существует много причин, по которым охраняемое авторским правом произведение может перейти в категорию «сиротских»:

- субъективного характера - безразличие и нежелание автора контролировать результат своего интеллектуального труда;

- объективного характера - утрата информации об авторе произведения из-за повреждения носителя или потери оригинала произведения; намеренное искажение третьими лицами информации об авторе; смена правообладателя и недоступность правопреемника, который может быть в том числе иностранным фризическим или юридическим лицом.

В соответствии со ст. 18(1) Бернской конвенции 1886 г. факт перехода произведения в общественное достояние связывается с истечением срока действия «авторского права имущественного характера» ${ }^{9}$. Именно такой подход закреплен в национальном праве современных государств ${ }^{10}$. При этом известно, что сроки охраны имущественных прав в разных государствах определяются по-разному, кроме того, ситуация осложнена конвенционным правилом о сравнении сроков (ст. 7(8) Бернской конвенции 1886 г.) $)^{11}$.

Как отмечалось, переход произведения в общественное достояние по национальному праву может происходить и в силу других причин: законодательных предписаний санкционного характера, добровольного отказа авторов от исключительных прав в пользу общества. Однако независимо от обстоятельств перехода произведениия под действие института общественного достояния, оно выходит из-под авторско-правовой охраны и, соответственно, течение срока охраны исключительных прав прекращается.

Важно также понять, в чью пользу снимаются ограничения на использование авторского произведения в случаях действия институтов общественного достояния и сиротских произведений.

Частично ответ на этот вопрос звучал при обсуждении на одной из конференций: перейдя в общественное достояние, произведение может быть использовано любым участником частноправовых отношений любыми законными способами ${ }^{12}$ без приобретения исключительных прав на само используемое (перешедшее в общественное достояние) произведение.

Правоприменительная практика многих государств свидетельствует в пользу пресечения попыток заинтересованных (третьих) лиц восстановить монопольное владение перешедшими в общественное достояние произведениями через механизм бессрочного действия моральных прав или через механизм авторских прав на произведения, производные от произведений, перешедших в общественное достояние ${ }^{13}$.

Private International Law: Comparative Perspectives. P. 780 ; Heath Ch. Intellectual Property Law in Asia. London, 2003. P. 27.

9 Липцик Д. Авторское право и смежные права. М., 2002. С. 233.

${ }^{10}$ См., например: ГК РФ. Ч. 1 ст. 1282.

${ }^{11}$ Дюсолье С. Указ. соч. С. 40.

12 Липцик Д. Указ. соч. С. 233.

${ }^{13}$ Дело 04-15.543 «Плон и др. против Пьера Гюго и др.» (фр. Sociétié Plon et autres v. Pierre Hugo et autres), решение № 125 (от 30.01.2007) Первой гражданской палаты Кассационного суда (Высокий суд Франции) // URL: www.legifrance.gouv.Fr. 
Анализ региональных и двусторонних соглашений разных государств в сфере охраны авторских прав позволяет прийти к выводу о том, что государства не распространяют договорные отношения на определение порядка действия института общественного достояния не только в рамках Бернской конвенции, но и в соответствии с другими международными соглашениями, оставляя этот вопрос в сфрере национального права каждого конкретного государства.

Наглядно позиция государств следовать коллизионной привязке «закон страны охраны произведения» (lex loci protectionis) ${ }^{14}$ в вопросах общественного достояния, т.е. следовать исключительно собственному праву, демонстрируется в судебном решении по делу Бриджменской библиотеки искусств против корпорации Корел (The Bridgeman Art Library, Ltd. v. Corel Corporation ${ }^{15}$ ). Одним из основных доводов библиотеки в американском суде была ссылка на конкретное правовое регулирование общественного достояния в иностранном правопорядке (Англия и Уэльс). Суд не принял этот довод, пояснив, что спор будет рассматриваться на основании американского права ${ }^{16}$.

Вопрос об определении правового статуса и режима общественного достояния ставился учеными еще во второй половине прошлого века ${ }^{17}$, но до сих пор не решен. Лишь некоторые государства ввели в свое законодательство по авторскому праву, помимо явной ссылки на общественное достояние, определение этого института: Алжир, Бразилия, Кения, Коста-Рика, Руанда, Чили. Однако эти определения носят описательный характер в отношении содержания, но не режима общественного достояния и не предусматривают санкций. Так, в ст. 7 Закона об авторском праве и смежных правах Коста-Рики закреплено: «Каждый может свободно пользоваться, в любой форме или в любом процессе, произведениями, принадлежащими общественному достоянию» ${ }^{18}$.

Исключением является Чили, где в Закон об интеллектуальной собственности $^{19} 1970$ г. в результате изменений в 2010 г. были внесены положения, предотвращающие возможность вернуть права на произведения, перешедшие в общественное достояние. Так, в ст. 80 установлен запрет на любые сознательные

14 Подробнее о коллизионном регулировании см.: Дмитриева Г. К., Луткова О. В. Тенденции развития коллизионного регулирования трансграничных авторских отношений, не связанных напрямую с коммерческим использоваанием произведения // Вестник Университета имени О.Е. Кутафина (МГЮА). 2019. № 10 (62). С. 27-38.

15 The Bridgeman Art Library, Ltd. v. Corel Corporation; $36{ }^{\circ}$ F. Supp. 2d 191. S.D.N.Y. $1999 / /$ URL: http://www.constitution.org/1ll/court/fed/bridgman.html.

${ }^{16}$ Hanson M. The Right to Display Public Domain Images // URL: http://englishhistory.net/art/. March 6, 2015.

${ }_{17}$ Lange D. Recognizing the Public Domain // Law and Contemporary Problems. 1981. Vol. 44. P. 147.

18 Закон № 6683 «Об авторском праве и смежных правах» (с изм., внесенными Законом № 8834 от 03.05.2010) // URL: http://www.wipo.int/wipolex/ru/details.jsp?id=11316 (текст на испанском языке).

19 Закон № 17.336 «Об интеллектуальной собственности» 1970 г. (с изм., внесенными Законом № 20.435 от 24.05.2010) // URL: http://www.wipo.int/wipolex/ru/text.jsp?file_id=270205 (текст на английском языке). 


\begin{tabular}{|c|c|}
\hline 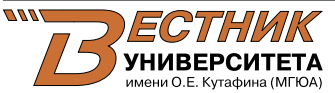 & $\begin{array}{l}\text { Луткова О. В. } \\
\text { Разграничение действия институтов общественного достояния } \\
\text { и сиротских произведений в трансграничных авторских отношениях }\end{array}$ \\
\hline
\end{tabular}

попытки воспроизвести, распространить, предоставить или обнародовать произведение, принадлежащее общественному достоянию, под именем, которое не является именем его настоящего автора; любые обманные требования в отношении имущественных прав на произведение, принадлежащее общественному достоянию. Такое правовое регулирование, хотя и не снимает абсолютно всех вопросов относительно общественного достояния, без сомнения, является положительной тенденцией и примером для мирового сообщества.

Попытки легализовать доступ к сиротским произведениям предприняты в правовых системах ряда государств, и к настоящему времени ЕС и более 20 государств уже приняли национально-правовые акты или акты негосударственного характера, регулирующие этот вопрос: в ЕС - Директива Европейского парламента и Совета Европейского Союза 2012/28/ЕС от 25.10.2012 об определенном разрешенном использовании произведений, не определяемых по субъекту авторского права ${ }^{20}$ (далее - Директива); в Канаде, Японии, Индии, Южной Корее - нормы в законодательстве; в США - документ неюридического характера ${ }^{21}$ - доклад Бюро по охране авторских прав в США «Сиротские произведения и массовая оцифровка» 2015 г.

Модели регулирования отношений по поводу сиротских произведений в разных государствах значительно различаются, а правоприменительная практика по выбору применимого права к трансграничным спорам не сформировалась. Легализацию доступа к сиротским произведениям можно свести к двум основным подходам. При подходе opt-in правообладатель, действуя пассивно, считается по умолчанию не согласным на использование своего произведения, но третьи лица при соблюдении условий могут получить разрешение от государства (ЕС, Германия, Канада, Япония, Индия, Южная Корея). В рамках подхода opt-out правообладатель считается по умолчанию согласным на использование произведения, но имеет возможность отказаться, действуя активно (Франция, Великобритания).

Оба рассматриваемых института авторского права объединяет ситуация потенциально существующей возможности возврата произведения из статуса общественного достояния или из сиротских произведений под авторско-правовую охрану.

Авторско-правовая охрана на произведения, перешедшие в общественное достояние, может быть восстановлена в результате продлений военного времени, реабилитации подвергшегося репрессиям автора, признания недействительным

20 Директива Европейского парламента и Совета Европейского Союза 2012/28/ЕС от 25.10.2012 об определенном разрешенном использовании произведений, не определяемых по субъекту авторского права // СПС «Гарант».

21 Попытки урегулировать доступ к «сиротским» произведениям на законодательном уровне в США предпринимались с конца прошлого века, но не были успешны. См. об этом: Dispute settlement: Dispute DS160. World Trade Organization // URL: https://www.wto.org/ english/tratop_e/dispu_e/cases_e/ds160_e.htm ; Peters M. The Importance of Orphan Works Legislation. U. S. Copyright Office // URL: https://www.copyright.gov/orphan/; Открытая библиотека. Рекомендации для библиотек по использованию открытых лицензий и публикации произведений в режиме открытого доступа / С. А. Козловский , А. С. Горбунова, Д. А. Жуков [и др.] ; под общ. ред. С. А. Козловского. М. : Ваш формат, 2017. С. 100. 
акта добровольной передачи автором произведения в общественное достояние, вступления государства в международное соглашение с соответствующими обязательствами и по другим причинам; на произведения, получившие статус сиротских, - в результате выявления обладателя прав.

В связи с этим целесообразно подвергнуть анализу риски, которые возникнут в случае, если произведение, получившее соответствующий статус (сиротского или общественного достояния), было правомерно использовано третьими лицами, включая иностранные, в разрешенных пределах, в том числе для создания производных версий, после чего первичное произведение восстановлено из сиротских или из общественного достояния под авторско-правовую охрану.

Последствия восстановления отдельных произведений под охрану авторского права для трансграничных отношений можно оценить на следующем примере. Российская Федерация в 1994 г., присоединяясь к Бернской конвенции 1886 г. в редакции 1971 г., сделала оговорку об отказе от исполнения статьи об обратной силе Конвенции ${ }^{22}$, подчеркнув, что «действие Бернской конвенции... не распространяется на произведения, которые на дату вступления этой Конвенции в силу для Российской Федерации уже являются на ее территории общественным достоянием» ${ }^{23}$. Однако гораздо позднее, в процессе подготовки к вступлению в ВТО, мировое сообщество потребовало от Российской Федерации соответствия ее законодательства мировым стандартам, в том числе в сфере регулирования авторских прав.

С целью вступления в ВТО оговорка к статье об обратной силе Бернской конвенции 1886 г. была официально снята Российской Федерацией в 2012 г. ${ }^{24}$, а изменения в отечественное законодательство начали вноситься значительно раньше. Соответственно, ряд произведений иностранных авторов, которые на территории России на момент присоединения к Бернской конвенции 1886 г. находились в общественном достоянии, вернулись под охрану авторского права. Это произошло главным образом по причине того, что в Бернской конвенции 1886 г. предусмотрен более длительный срок охраны авторских прав, чем в действовавшем до вступления в Конвенцию отечественном законодательстве; а также в силу того, что участие России в Бернской конвенции 1886 г. расширило круг государств, с которыми Россия оказалась связанной договорными отношениями в сфрере авторских прав ${ }^{25}$.

22 Конвенция вступила в силу для России в 1995 г.

${ }^{23}$ Постановление Правительства РФ от 03.11.1994 № 1224 «О присоединении Российской Федерации к Бернской конвенции об охране литературных и художественных произведений в редакции 1971 года, Всемирной конвенции об авторском праве в редакции 1971 года и дополнительным Протоколам 1 и 2, Конвенции 1971 года об охране интересов производителей фонограмм от незаконного воспроизводства их фонограмм». П. 2 // СПС «Гарант».

24 Постановление Правительства РФ от 11.12.2012 № 1281 «Об отзыве заявления, сделанного при присоединении Российской Федерации к Бернской конвенции об охране литературных и художественных произведений» // СПС «Гарант».

${ }^{25}$ В соответствии с действовавшим ранее законодательством, произведениям, которым на территории России никогда не предоставлялась охрана, также считались перешедшими 


\begin{tabular}{|c|c|}
\hline 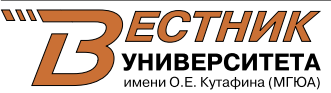 & $\begin{array}{l}\text { Луткова О. В. } \\
\text { Разграничение действия институтов обцественного достояния } \\
\text { и сиротских произведений в трансграничных авторских отношениях }\end{array}$ \\
\hline
\end{tabular}

В связи с обозначенной ситуацией, в частности, в 2008 г. возник ряд проблем с репертуаром отечественных театров. Так, театру имени Вахтангова иностранный правообладатель запретил продолжать постановку пьесы «Милый лжец» (Джером Килти, 1957 г.), которая к этому моменту шла в нем уже 14 лет. Также иностранные обладатели прав на произведение «Трехгрошовая опера» (Бертольд Брехт, 1931 г.) запретили МХАТу продолжать постановку пьесы в переработанном виде под угрозой штрафра и полного запрета постановки. Были запрещены пьесы Юкио Мисимы, в частности, «Маркиз де Сад» в Молодежном театре г. СанктПетербурга, а по всей России - постановка пьесы «Двенадцать разгневанных мужчин» Р. Роуза и многие другие.

Таковы для практики трансграничных авторско-правовых отношений возможные последствия восстановления произведений в охране из статуса сиротских или из общественного достояния. В подобных случаях затрагиваются права не только первичных авторов и лиц, вступивших с ними в договорные отношения, но также третьих лиц, правомерно воспользовавшихся объектами общественного достояния или объектами в статусе сиротских произведений и создавших на их основе производные произведения.

В этом случае относительно производного произведения возникает ряд вопросов, ключевыми из которых являются: правомерно ли в принципе существование производного произведения; можно ли продолжать эксплуатацию производного произведения, если первичный автор (правообладатель) возражает; действуют ли правомерно заключенные трансграничные договоры о передаче авторских прав на производное (от сиротского или перешедшего в общественное достояние) произведение и зависит ли ситуация от вида договора (отчуждение, лицензирование); какой правопорядок компетентен регулировать соответствующее трансграничное авторское отношение.

В настоящее время правовое регулирование трансграничных отношений, возникающих в связи с восстановлением произведений в авторско-правовой охране в национальных правопорядках государств отсутствует, как правило, не только на коллизионном, но и на материально-правовом уровне. Исключением являются некоторые нормы в праве США.

Так, для определения применимого права при установлении принадлежности восстановленных исключительных прав автора в Кодексе США предписано применять коллизионную привязку «закон страны происхождения произведения» (lex loci originis): восстановленные права принадлежат «автору или начальному правообладателю в соответствии с законом страны происхождения произведения» (§ 104 A 2 (b) 17 USC) $)^{26}$.

Кроме того, в Кодексе США урегулированы также отношения по поводу восстановленных прав между автором первичного произведения (начальный правообладатель) и лицом, правомерно создавшим на основе этого (на тот момент сиротского или перешедшего в общественное достояние) произведения, авторские права на которое были впоследствии восстановлены, новое (производное)

в общественное достояние (Закон РФ от 09.07.1993 № 5351-І «Об авторском праве и смежных правах» (с изм. и доп. ; утратил силу). П. 1 ст. 28 // СПС «Гарант»).

2617 U. S. Code // URL: https://www.law.cornell.edu/uscode/text/17/104. 
произведение (§ 104 A (d) (3) 17 USC) ${ }^{27}$. Авторам производных от восстановленных в охране произведений разрешается продолжать использование своих произведений при условии выплаты обладателю прав на оригинал разумного вознаграждения, размер которого при отсутствии договоренности сторон может определить суд ${ }^{28}$.

Законодательный опыт США, несомненно, интересен и должен быть изучен с точки зрения как юридической техники, так и практики применения. Из-за отсутствия во внутреннем праве большинства государств соответствующих норм их правоприменительные органы лишены механизма рассмотрения споров, связанных с проблемой регулирования трансграничных отношений в связи с восстановлением произведений в авторско-правовой охране.

При этом тенденции, связанные с усилением в последние десятилетия внимания к проблеме сиротских произведений и произведений общественного достояния, введением многими государствами юридических норм, позволяющих авторам отказываться от исключительных прав, развитием движения creative commons, и многие другие тенденции свидетельствуют о том, что количество спорных ситуаций в связи с трансграничными отношениями по поводу восстановленных в авторско-правовой охране произведений может увеличиваться и, следовательно, требует нормативного регулирования.

Возможно подвести итоги исследования ключевых различий в действии института общественного достояния и института сиротских произведений в трансграничных авторских отношениях.

Институт общественного достояния является общепризнанным институтом авторского права, поскольку закреплен в универсальном международном соглашении, участниками которого являются более 174 государств мира (Бернская конвенция 1886 г.). Положение института сиротских произведений, напротив, в настоящее время нестабильно: несмотря на то, что существование проблемы произведений с неустановленным правообладателем бесспорно, действенного механизма ее разрешения, который не противоречил бы концепции исключительных прав, не выработано. Попытки урегулировать этот вопрос происходят в основном на национальном уровне в немногих (менее 30) государствах.

В настоящее время возможны, по крайней мере, следующие случаи перехода произведений под действие института общественного достояния: истечение срока авторско-правовой охраны (конвенционное предписание); императивные законодательные предписания санкционного характера (непредоставление охраны произведениям авторов из государств с недостаточным уровнем охраны иностранных произведений); добровольный отказ авторов от исключительных прав в пользу общества. При совершенно иных обстоятельствах произведения переходят под действие института сиротских произведений: нежелание автора осуществлять контроль или утрата сведений об авторе или его местонахождении.

2717 U. S. Code.

${ }^{28}$ См. об этом также: Будылин С. Л. Винни-Пух и Чебурашка встречаются в суде : Споры вокруг «старых» произведений в России и за рубежом // Журнал Суда по интеллектуальным правам. 2014. № 4. С. 53-66. 
Критерии разграничения институтов общественного достояния и сиротских произведений также просматриваются в определениях, даваемых объектам охраны: общественное достояние - произведения, которые не находятся под охраной авторского права, так как срок охраны истек или по другим причинам; сиротские произведения, напротив, предположительно находятся под охраной авторского права, но установить правообладателя или место его нахождения не представляется возможным.

Институт общественного достояния закреплен в праве всех государств мира, участвующих в системе международной охраны авторских прав, и его действие можно считать гармонизированным, несмотря на различия в исчислении сроков перехода произведений в общественное достояние и отсутствие устойчивых дефиниций в национальном праве государств. Также, несмотря на отсутствие специального законодательно закрепленного коллизионного регулирования, правоприменительная практика государств свидетельствует о единой тенденции выборе для разрешения трансграничных споров исключительно собственного права (lex loci protectionis). Механизмы законодательного или негосударствнного доступа к сиротским произведениям существуют лишь в немногих государствах, и в них отсутствует единообразие: в одних государствах это закрепление возможности использовать сиротские произведения только на индивидуальной основе, в других - разрешение лицензирования в массовых масштабах. Коллизионное регулирование в этой сфере еще не сложилось.

Тем не менее оба рассматриваемых института - общественного достояния и сиротских произведений — на трансграничном уровне объединяет проблема отсутствия правового регулирования для ситуации возврата произведения из-под регулирования соответствующего института под полноценную авторско-правовую охрану. Для такой ситуации отсутствуют как коллизионные, так и материальноправовые нормы. Выходом из данной ситуации может послужить опыт законотворчества США, закрепивших коллизионный подход lex loci originis для определения применимого права при установлении принадлежности восстановленных исключительных прав, а также урегулировавших отношения по поводу восстановленных прав между автором первичного произведения и лицом, правомерно создавшим на основе начального произведения собственное (производное) произведение.

\section{БИБЛИОГРАФИЯ}

1. Будылин С. Л. Винни-Пух и Чебурашка встречаются в суде : Споры вокруг «старых» произведений в России и за рубежом // Журнал Суда по интеллектуальным правам. - 2014. - № 4. - С. 53-66.

2. Дмитриева Г. К., Луткова О. В. Тенденции развития коллизионного регулирования трансграничных авторских отношений, не связанных напрямую с коммерческим использованием произведения // Вестник Университета имени О.Е. Кутафина (МГЮА). — 2019. — № 10 (62). — С. 27-38.

3. Дюсолье С. Обзорное исследование по авторскому праву и смежным правам и общественному достоянию / Комитет по развитию и интеллектуальной собственности. 7-я сессия. - Женева, 2-6 мая 2011 г. 
4. Левова И. Ю., Винник Д. В., Моисеева А. Ю. Сиротские произведения в России: статус, пути решения проблемы : Как открыть доступ к произведениям, авторов или законных правообладателей которых установить невозможно. М., 2016. - 66 c.

5. Липцик Д. Авторское право и смежные права. - М., 2002. - 776 с.

6. Луткова О. В. Общественное достояние в международном авторском праве // Интеллектуальная собственность. Авторское право и смежные права. 2016. — № 3. - С. 45-58.

7. Луткова О. В. Принципы правового регулирования трансграничных авторских отношений // Вестник Университета имени О.Е. Кутафина (МГЮА). 2016. № 12 (28). С. 63-92.

8. Открытая библиотека. Рекомендации для библиотек по использованию открытых лицензий и публикации произведений в режиме открытого доступа / С. А. Козловский , А. С. Горбунова , Д. А. Жуков [и др.] ; под общ. ред. С. А. Козловского. - М. : Ваш фрормат, 2017. - 141 с.

9. Пузин Р. С. Проблема перехода сиротских произведений в общественное достояние // Вестник Самарской гуманитарой академии. - Серия «Право». 2018. - № 1 (20).

10. Ancel M.-E. France // Intellectual Property and Private International Law: Comparative Perspectives / ed. by T. Kono. - Oxford and Portland, Oregon, 2012. - 1032 p.

11. Hanson M. The Right to Display Public Domain Images // URL: http://englishhistory. net/art/. - March 6, 2015.

12. Heath Ch. Intellectual Property Law in Asia. — London, 2003. - 545 p.

13. Lange $D$. Recognizing the Public Domain // Law and Contemporary Problems. 1981. - Vol. 44. - P. 145-151.

14. Lee G. Korea // Intellectual Property and Private International Law: Comparative Perspectives / ed. by T. Kono. — Oxford and Portland, Oregon, 2012. - 1032 p.

15. Peters M. The Importance of Orphan Works Legislation // U. S. Copyright Office. URL:https://www. copyright.gov/orphan/. 